\title{
Single grain grinding: a novel approach to model the interactions at the grain/bond interface during grinding
}

\author{
Berend Denkena $^{1} \cdot$ Abdelhamid Bouabid $^{1} \cdot$ Alexander Kroedel $^{1}$ \\ Received: 3 January 2020 / Accepted: 16 March 2020 / Published online: 7 May 2020 \\ (C) The Author(s) 2020
}

\begin{abstract}
The influence of the bond on grinding processes remains one uncertainty in the investigation of grinding tool behavior. Among others, this is due to the lack of knowledge about the interactions between the grain/bond interface and the grinding process loads. Understanding these interactions allows for further process development by adjusting the bond to the grinding application. The interactions at the grain/bond interface during grinding depend on the single grain thermomechanical loads as well as the tool properties. This paper presents an approach to provide the boundary conditions which are needed to model the interactions at the grain/bond interface. The machining of tungsten carbide with a bronze-bonded diamond tool is considered as use case. For this purpose, a novel kind of tool extracted from the grinding layer that serves to quantify the loads affecting the active grains and consequently their grain/bond interfaces during grinding is developed. The results of different grain orientations are plotted in a so-called $\mathrm{A}_{\mathrm{cu}}$ diagram, which gives an overview of the mechanical loads for different grain orientations and chip thickness values, as they occur during grinding due to the stochastic orientation and distribution of the abrasive grains in the grinding tool. It is shown that depending on the engagement conditions, the single grain-cutting force can reach up to $300 \mathrm{~N}$ by chip thickness values of $20 \mu \mathrm{m}$, which implies different wear behavior of the active grains.
\end{abstract}

Keywords Grinding $\cdot$ Modeling $\cdot$ Grain/bond interface $\cdot$ Bronze bond $\cdot$ Tool wear

\section{Introduction}

Bronze-bonded grinding tools are the most common type of tools used among the sintered metal-bonded grinding tools [1, 2]. The properties of these tools can be varied in a wide range during manufacturing by modifying the powder mixture and the sintering parameters [3, 4]. Bronze bonds are often combined with superabrasives, such as diamond and polycrystalline cubic boron nitride $[1,2,5]$. Due to the high strength of this bond type in combination with the high ductility as well as the high thermal conductivity, bronze-bonded grinding tools are predestined for the machining of brittle and hard materials, such as tungsten carbide, ceramics, and glass [1,2]. During machining, the bronze bond is subject to mechanical loads. If

Abdelhamid Bouabid

bouabid@ifw.uni-hannover.de

1 Institute of Production Engineering and Machine Tools (IFW),

Leibniz Universität Hannover, An der Universität 2,

30823 Garbsen, Germany these loads are beyond the bond strength, it will deform plastically and therefore will affect the process and lead to grain breakout [6].

Modeling the grinding process enables the understanding of the grinding behavior and therefore improves the efficiency of the process [7]. The grinding behavior of a grinding tool summarizes the aspects of workpiece quality, process forces, and tool wear [8]. In the literature, there are a large number of models to explain and to predict the grinding process. Models that consider whole grinding tools are defined as macroscopic models. The macroscopic models are typically analytical or numerical models based on microscopic models, chip thickness models, and topography models [9-12]. Microscopic models are built with analogy methods, such as single grain cutting which provides basic knowledge about the interdependencies between the abrasive grain and the process behavior on a microscopic scale [9, 10, 13-20]. The single grain-cutting tool consists of one abrasive grain which is glued or soldered onto the tip of a stick-shaped metal body. Since the grain bonding of single grain-cutting tools strongly simplifies the bond matrix of grinding tools, the interactions at the grain/ bond interface are depicted insufficiently by single grain 
cutting [9-20]. As a result, there is a knowledge deficit about the influence of the grain/bond interface on the grinding behavior. Reducing this knowledge deficit is of high scientific relevance, as it allows better understanding of the grinding process and the adjustment of the bond to the grinding application.

The interactions at the grain/bond interface during grinding depend on the interface properties as well as the single grain thermomechanical loads. These loads, in turn, are defined by the engagement conditions of the grain with the workpiece. Therefore, the main objective of this research work is to develop a method which allows the single grain loads during grinding dependent on the engagement conditions to be defined. This method is called single grain grinding. It represents a further development of the single grain cutting by taking the bond and the engagement conditions into consideration. In the future, the single grain grinding will form the base for modeling the interactions at the grain bond interface.

\section{Single grain tool with consideration of the bond}

To determine the single grain thermomechanical loads, the single grain-cutting process is applied. However, the use of conventional tools is avoided. Instead, a novel tool which takes the bond into consideration is developed. The underlying idea of this development is to use the actual grinding tool bond for single grain cutting experiments. For this purpose, pyramidal segments are produced from a bronze-bonded grinding wheel in several steps (Fig. 1).

The first step consists of the manufacturing of a grinding wheel (1). This step is carried out with a Dr. Fritsch DSP 510 sintering press. For this step, an initial mixture of bond powder containing 90 at $\%$ copper and 10 at $\%$ tin from Dr. Fritsch as well as cubo-octahedral diamond grains with the specification FMD60 from Van Moppes is used. The grain size and the grain concentration are $\mathrm{D} 181$ and $\mathrm{C} 100$, respectively. Subsequent to the manufacturing, the grinding layer is cut with a water jet into a geometry similar to a gearwheel (2). Then, a triangular profile is generated on the layer with a stationary dresser (3). Afterwards, the grinding layer is separated from the wheel body with a water jet (4). Following this step, the resulting ring is broken down manually into several pyramidal segments, the so-called grinding pyramids. The grinding pyramids are later glued to a steel body (5). A modified wheel body with balancing holes and a clamping system is used to mount the novel tools. Finally, a grain is uncovered by machining a sharpening stone using a surface-grinding machine (6). The tools that can be used for single grain grinding must have a single grain on the tip after sharpening. The final inspection and sorting of the tools are carried out with the aid of a light microscope from Keyence. A total of 13 tools are selected for the following investigations.

Figure 2 shows the experimental setup. For the experiments, a Geibel+Hotz surface-grinding machine is used. The axial kinematics on an inclined sample is selected. This kinematics corresponds to the circumferential surface grinding, to which an axial feed motion is superimposed. Equidistant scratches of different depths are produced via a suitable combination of feed speed and cutting velocity. Each scratch is analyzed by means of chip thickness $\mathrm{h}_{\mathrm{cu}}$ and corresponding chip cross-sectional area $\mathrm{A}_{\mathrm{cu}}$ (Fig. 2). For this purpose, a laser microscope $\mu$ scan from NanoFocus AG is used. Furthermore, the process forces in normal, tangential, and axial direction of each scratch are measured with a MiniDyn 9256-C from

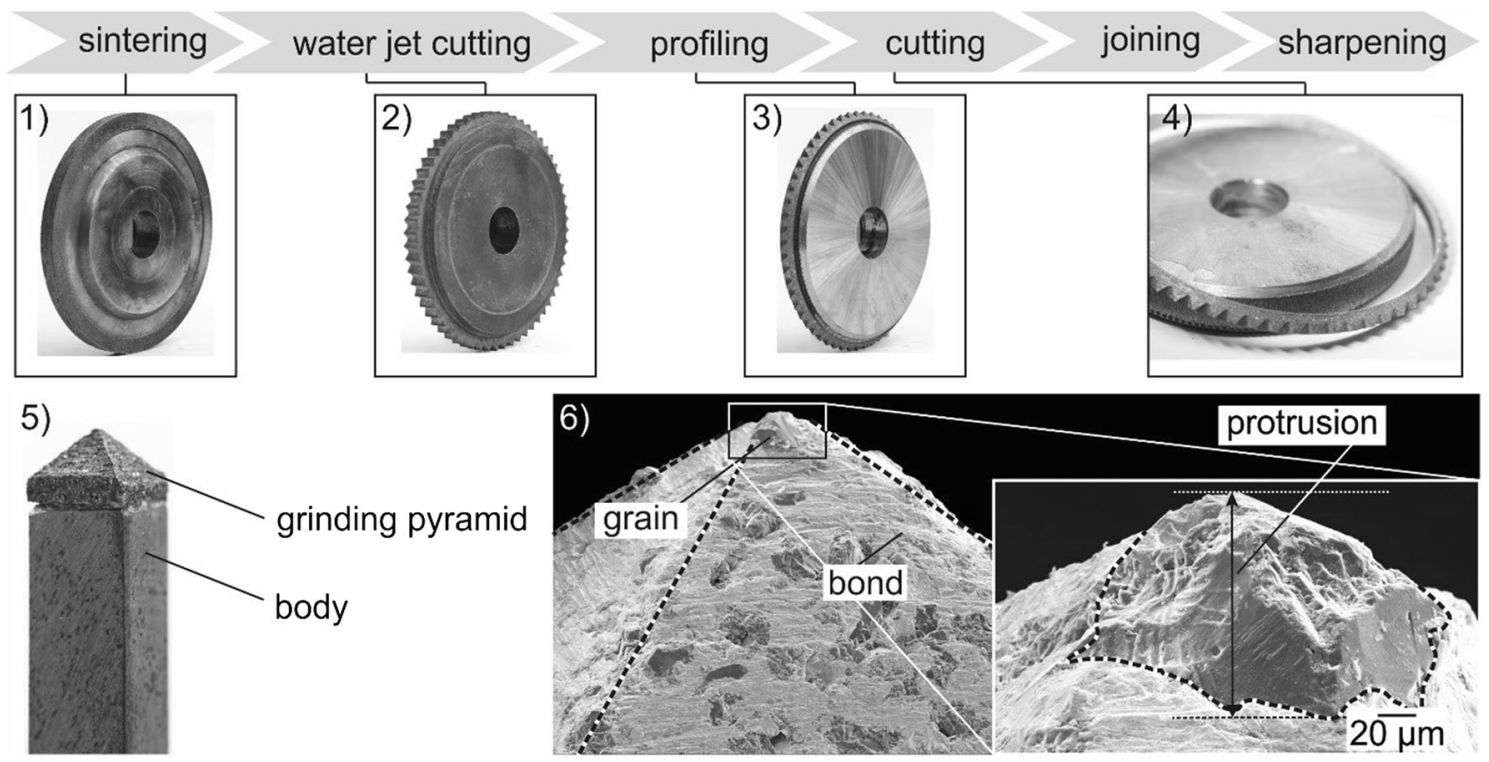

Fig. 1 Novel single grain-cutting tool 


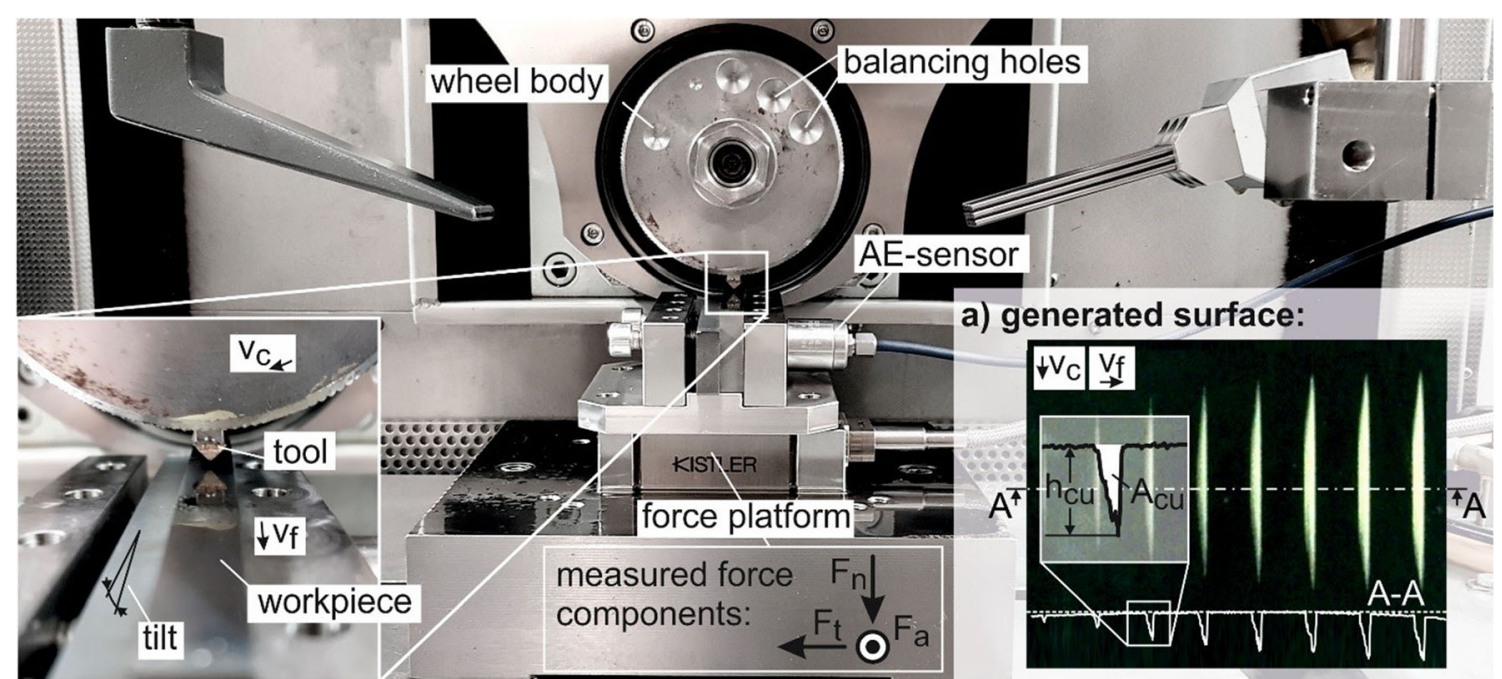

Fig. 2 Experimental setup of single grain grinding

Kistler. For the purpose of evaluation, the maximum forces are assigned to the maximum scratch depths. To increase the data quality, polished tungsten carbide ( $10 \%$ cobalt, $0.9 \mu \mathrm{m}$ tungsten carbide grain size) samples are used in the experiments. Prior to the tests, a lubricating oil film is spread on the samples' surface to produce lubrication conditions similar to the grinding process. To analyze tool topographies, a scanning electron microscope (SEM) EVO60 from Carl Zeiss is used.

\section{Tool wear in single grain grinding}

The bond wear of the novel tool provides information on its suitability for investigating the interactions at the grain/bond interface. In this section, the wear of the novel tool during single grain grinding is investigated and compared with the wear of a grinding wheel during grinding. To achieve comparable types of wear, the grinding tool is sintered with the same specification as the tool used to manufacture the single grain tools. Furthermore, the same workpiece specification is used in both processes.

To emphasize the bond deformation of the single graincutting tool, tool wear is provoked by cutting scratches with chip thickness values higher than $\mathrm{h}_{\mathrm{cu}}=20 \mu \mathrm{m}$, which are unusually high values in comparison with $\mathrm{h}_{\mathrm{cu}}$ values below $10 \mu \mathrm{m}$ for grinding. Figure 3 shows a scanning electron microscope micrograph (SEM-micrograph) of a worn tool. Both grain-related and bond-related wear types can be identified in this image. The grain-related types of wear are adhesive wear and grain splintering. The plastic deformation represents the bond-related wear. This wear type was also reported by reference [6]. According to [6], progressive bond wear leads to a penetration of the bond by the grain or to a complete grain breakout.
To explore the extent of the plastic deformation at the grain/ bond interface, a cross-section of the worn tool is prepared. To realize this, the worn tool is separated in the grinding direction, embedded in a synthetic resin mass, ground, and polished. Figure 4 shows a SEM-micrograph of the crosssection generated by this way. Deformed grain boundaries and deformed pores can be detected on this graph. As a result of the mechanical single grain loads transmitted to the interface, the interface deforms plastically and the bond socket expands. These deformations extend for up to $3 \mu \mathrm{m}$ in the considered area, which weakens the retention of the grain in the bond. The deformations are supported by the pure form-fit connection between the grain and the bond, as no chemical reactions occur at the interface during manufacturing. These results prove that the developed tool enables the investigation of the grain/bond interface by correlating the deformations with the boundary conditions of the single grain-grinding process. In the following, the wear types during grinding are considered to validate the suitability of the developed tool.

The initial topography of the cylindrical grinding tool used for the validation is generated by profiling with a \#70-SiC form roll $\left(\mathrm{q}_{\mathrm{d}}=-0.8 ; \mathrm{v}_{\mathrm{cd}}=9.3 \mathrm{~m} / \mathrm{s} ; \mathrm{v}_{\mathrm{fad}}=743 \mathrm{~mm} / \mathrm{min} ; \mathrm{a}-\right.$ ed $=0.2 \mathrm{~mm}$ ) and sharpening with a \#60-corundum sharpening stone $\left(\mathrm{a}_{\mathrm{es}}=2 \mathrm{~mm} ; \mathrm{v}_{\mathrm{fs}}=300 \mathrm{~mm} / \mathrm{min} ; \mathrm{v}_{\mathrm{cs}}=15 \mathrm{~m} / \mathrm{s}\right)$. Both dressing tools use a vitrified bond. Subsequent to the dressing process, deep feed-grinding experiments of tungsten carbide are carried out. To observe tool wear, a sufficiently high specific material removal of $\mathrm{V}^{\prime}{ }_{\mathrm{w}}=1500 \mathrm{~mm}^{3} / \mathrm{mm}$ is machined. The experiment is carried out with a depth of cut of $\mathrm{a}_{\mathrm{e}}=$ $0.5 \mathrm{~mm}$, a cutting speed $\mathrm{v}_{\mathrm{c}}=15 \mathrm{~m} / \mathrm{s}$, and a workpiece speed $\mathrm{v}_{\mathrm{f}}=100 \mathrm{~mm} / \mathrm{min}$. By this parameter combination, the single grain chip thickness lies by $\mathrm{h}_{\mathrm{cu}}=1.5 \mu \mathrm{m}$ [21].

Figure 5 depicts SEM-micrographs of the tool surface after sharpening and after grinding. After sharpening, the tool topography shows intact abrasive grains with high protrusions 
Fig. 3 Wear types during single grain grinding

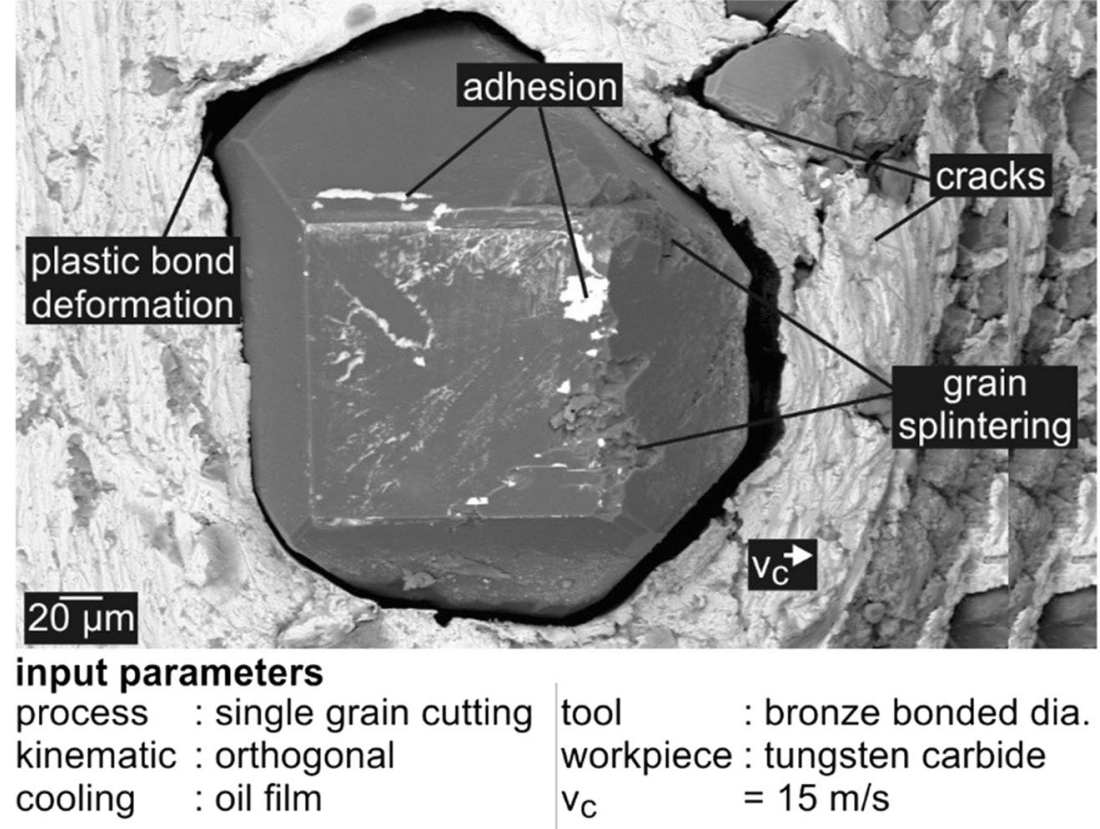

that are firmly embedded in the bond matrix. The grains have bond backs, which are created by the flow of the sharpening medium around the abrasive grain during conditioning. After grinding, both grain and bond wear can be observed. The grain wear types are adhesion, abrasion, and splintering. Furthermore, the bond sockets have expanded due to plastic deformations. Additionally, the plastic deformations have caused a diamond grain to sink into the bond, so that the protrusion is reduced and the bond back comes into contact with the workpiece. This leads to increased friction in the process and consequently to rising process temperatures.
Bond deformations, which occur during single grain grinding, also occur during grinding. This fact confirms the suitability of the novel tool to investigate the influence of the bond on the process behavior at a microscopic scale. Nevertheless, the wear types during single grain grinding are exclusively mechanical wear types. This is attributed to the different thermal boundary conditions of both processes regarding the contact zone temperature and the tool temperature: During grinding, the contact zone is pre-heated by the engagement of multiple grains. In addition, the structure of the single grain tool allows better cooling during the cut interruption.

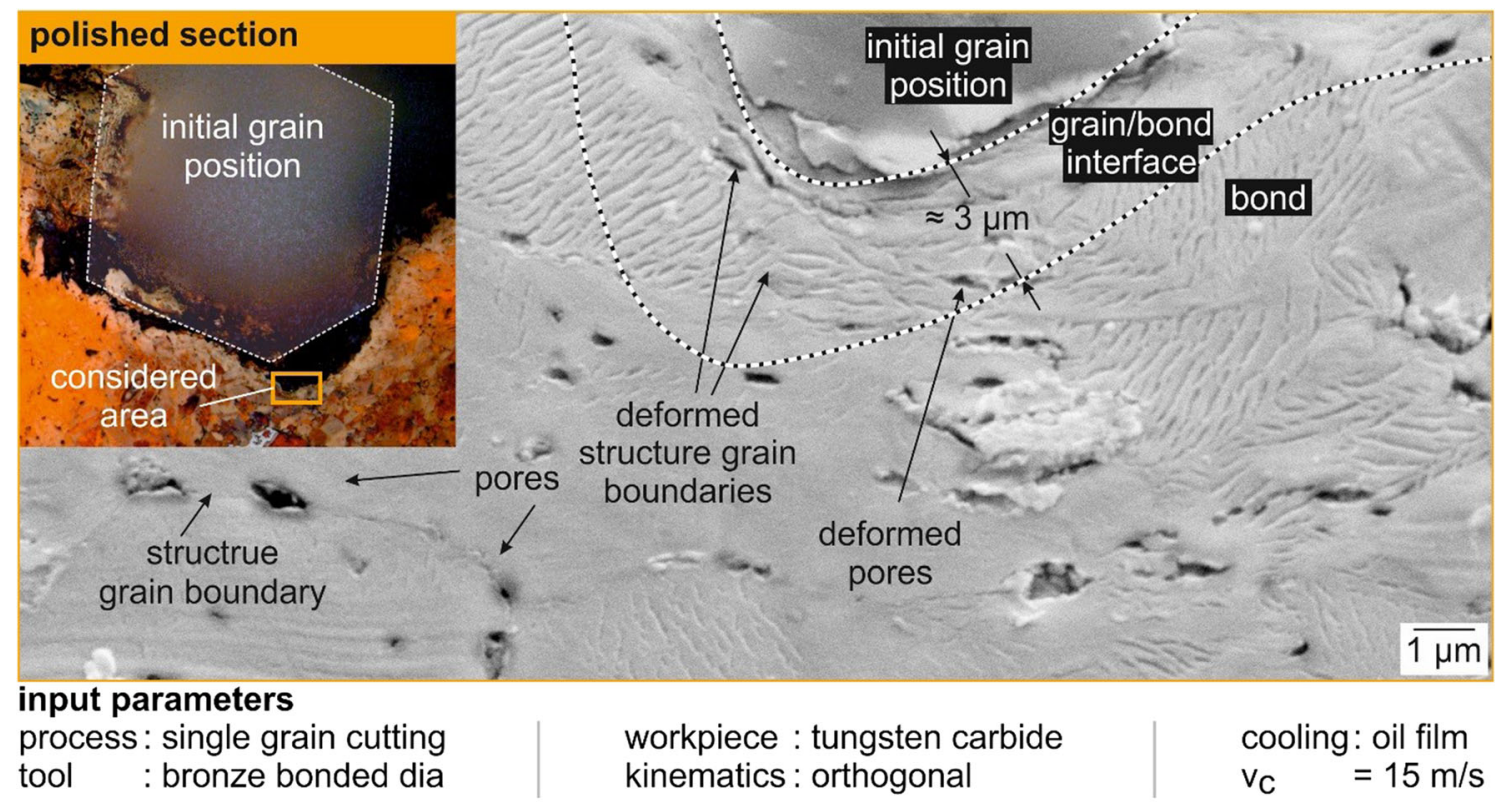

Fig. 4 Deformations at the grain/bond interface 


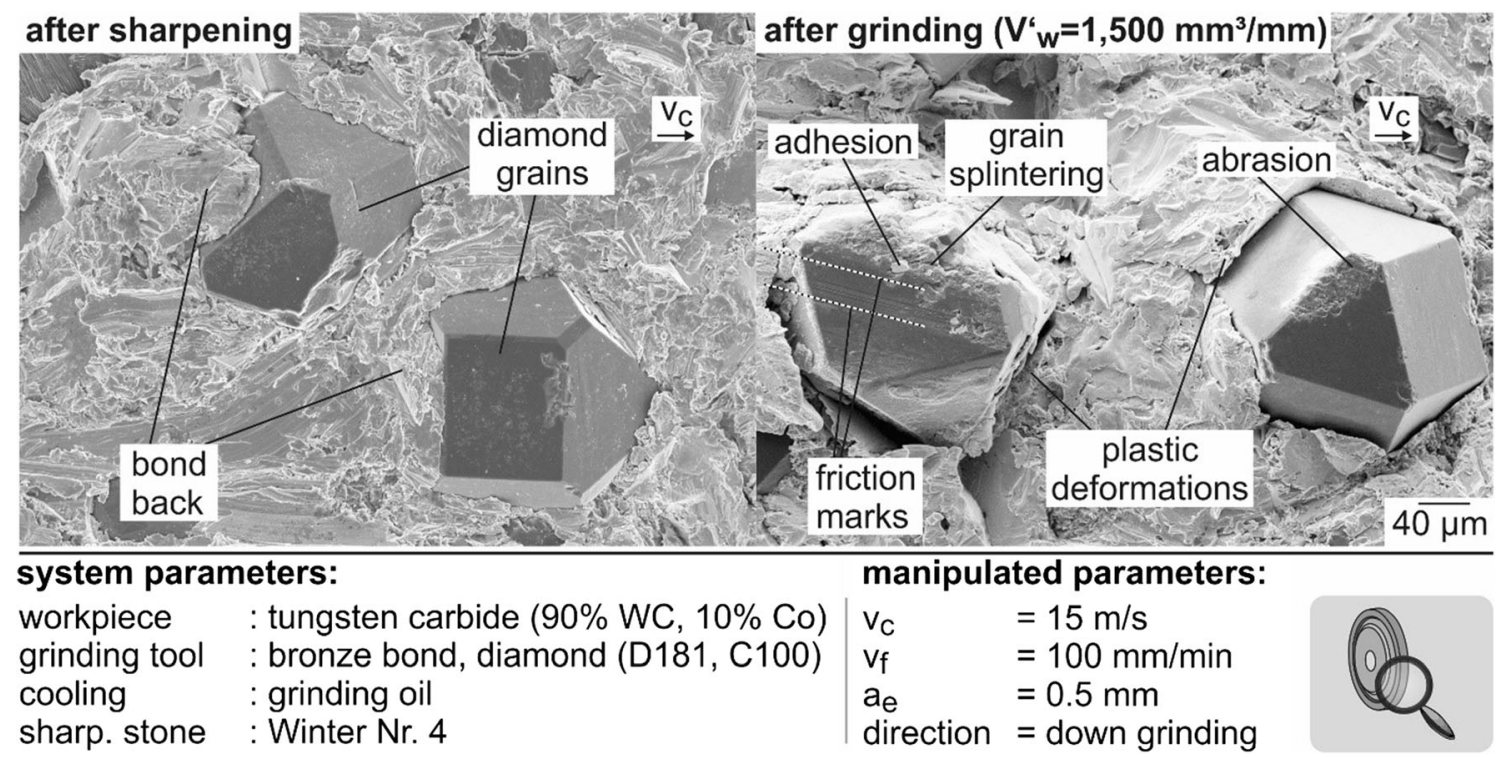

Fig. 5 Wear types during grinding

\section{Modeling the engagement conditions of single grains}

The engagement conditions with the workpiece surface during grinding define the thermomechanical loads of each single grain. As the abrasive grains are randomly oriented and stochastically distributed, a methodical evaluation of the different engagement conditions of the abrasive grains is required. For this purpose, chip cross-sectional area values resulting from all possible grain orientations are determined and plotted against different chip thickness values.

To create this model, a software tool, which determines the possible engagement conditions on the basis of a geometric grain model built according to the cubo-octahedral diamond grain used for manufacturing (Fig. 6a), is developed. This is achieved by tilting the grain model in one-degree steps along the $X, Y$, and $Z$ unit axes and characterizing the cutting edge by means of the chip cross-sectional area $\mathrm{A}_{\mathrm{cu}}$.

During grinding, the chip cross-sectional area depends on the grain shape. Furthermore, it relies on the chip thickness $\mathrm{h}_{\mathrm{cu}}$, which is defined by the grinding parameters (cutting velocity $\mathrm{v}_{\mathrm{c}}$, depth of cut $\mathrm{a}_{\mathrm{e}}$, workpiece speed $\mathrm{v}_{\mathrm{f}}$ ), the grain protrusion, and the grain distribution. Therefore, for each theoretical grain orientation, the software tool increases the chip thickness $h_{c u}$ in 1- $\mu \mathrm{m}$ increments and determines the chip cross-sectional area $\mathrm{A}_{\mathrm{cu}}$ in each step. Thus, a chip crosssectional area curve is obtained as a function of the chip thickness $\mathrm{h}_{\mathrm{cu}}$. Due to the geometric constraints, an $\mathrm{A}_{\mathrm{cu}}$ curve can be described by a second degree polynomial. The $\mathrm{A}_{\mathrm{cu}}$ curves of all the grain orientations form an $\mathrm{A}_{\mathrm{cu}}$ diagram (Fig. 6b).

Grain orientations that imply triangular-shaped cutting edges exhibit smaller chip cross-sectional area values than grain orientations resulting in flat or spherical cutting edges and are therefore located at the bottom of the $\mathrm{A}_{\mathrm{cu}}$ diagram, whereas the latter are located in the upper part (Fig. 6b). Each position in the $\mathrm{A}_{\mathrm{cu}}$ diagram can be interpreted as a single grain-operating point covering a variety of different grain geometries.

\section{Operating points}

During the experimental investigations, each tool is used in three test series at the cutting speeds $\mathrm{v}_{\mathrm{c}}=10,15$ and $20 \mathrm{~m} / \mathrm{s}$. After each test series, the tools are evaluated regarding wear with the light microscope and, if necessary, rejected if grain breakouts or bond wears lead to bond friction, whereby the process forces are falsified.

Due to the used kinematics, each tool spans several operating points in the $\mathrm{A}_{\mathrm{cu}}$ diagram during the experiments. To characterize these experimentally determined operating points of each tool, they are set against the theoretical $\mathrm{A}_{\mathrm{cu}}$ curve that result from the grain orientation of the considered tool. As shown in Fig. 6, an $A_{c u}$ curve can be depicted as a quadratic function of the chip thickness. Therefore, to obtain the theoretical $\mathrm{A}_{\mathrm{cu}}$ curve of a given tool, all its operating points are interpolated with a second degree polynomial:

$\mathrm{A}_{\mathrm{cu}}=p_{1} h_{\mathrm{cu}}^{2}+p_{2} h_{\mathrm{cu}}$

Another method to determine the theoretical $\mathrm{A}_{\mathrm{cu}}$ curve is to create a CAD model of the tool from a laser microscope measurement. This CAD model can then be used to determine the chip cross-sectional area values for variable chip thickness values. However, it has been found that the method of interpolation of the experimental operating points is more accurate and less complex than the measurement method. 
a) grain geometric model:

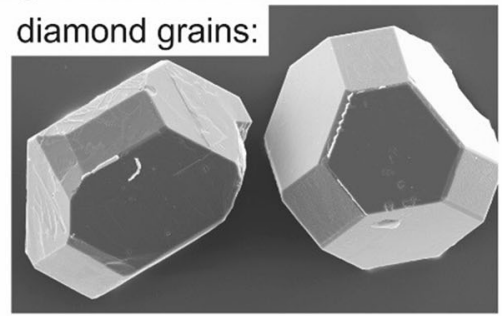

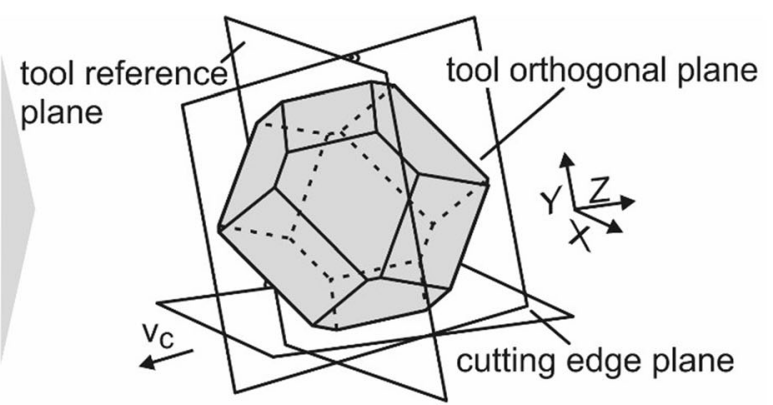

b) Acu-diagram $_{\text {cu }}$

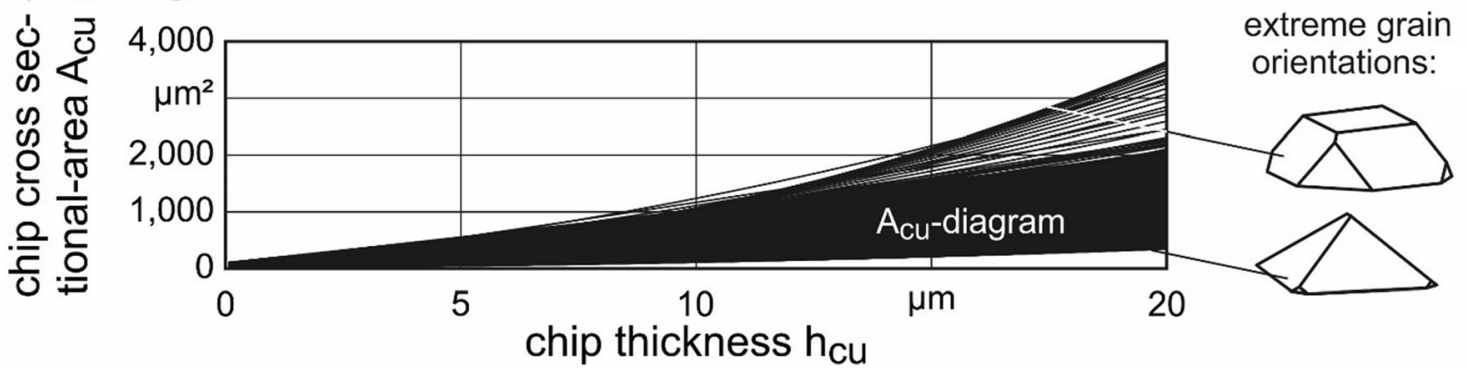

Fig. 6 Model of the engagement conditions

Table 1 in the appendix lists the interpolation data $\mathrm{p}_{1}$ and $\mathrm{p}_{2}$ as well as the quadratic error $R^{2}$ and the number of operating points per cutting speed and tool. The smallest quadratic error of the theoretical $\mathrm{A}_{\mathrm{cu}}$ curves is $R^{2}=0.89$, which indicates a high interpolation quality. In total, there are 298 operating points. While 129 operating points are obtained by the cutting speed $\mathrm{v}_{\mathrm{c}}=10 \mathrm{~m} / \mathrm{s}$, the numbers of operating points at $\mathrm{v}_{\mathrm{c}}=$ $15 \mathrm{~m} / \mathrm{s}$ and $\mathrm{v}_{\mathrm{c}}=20 \mathrm{~m} / \mathrm{s}$ correspond to 89 and 80 , respectively. This decreasing tendency is due to the elimination of some tools because of wear.

A reference tool is defined for the purpose of further analyses. Figure 7 shows the reference tool's operating points at different cutting speeds. In addition, the theoretical $\mathrm{A}_{\mathrm{cu}}$ curve is shown. The operating points deviate slightly from the theoretical $\mathrm{A}_{\mathrm{cu}}$ curve. Irrespective of the cutting speed, they are located above or below the theoretical $\mathrm{A}_{\mathrm{cu}}$ curve. These deviations are more noticeable with higher chip thicknesses.

The existing deviations between operating points and the theoretical $\mathrm{A}_{\mathrm{cu}}$ curve can be attributed to material separation mechanisms and dynamic loads. The tool is most likely subject to a high dynamic load with increasing chip thickness, which is reflected in a deflection and therefore a deviation of the chip cross-sectional area. Furthermore, from the SEM-micrographs of the scratches at the chip thickness values $\mathrm{h}_{\mathrm{cu}}=1.4 \mu \mathrm{m}$ and $\mathrm{h}_{\mathrm{cu}}=11.7 \mu \mathrm{m}$ in Fig. 8, smooth areas as well as breakouts can be identified. These phenomena indicate ductile and brittle material separation, which are typical for tungsten carbide machining [13]. The breakouts occur more frequently with higher chip thickness and lead to an increase of the effective chip crosssectional area against the theoretical value.

Due to the material separation mode and the dynamic loads during single grain grinding, slight displacements of the operating points may occur. At the same time, the theoretical $\mathrm{A}_{\mathrm{cu}}$ curves describe the theoretical position of the operating points if there are no deviations. Figure 9 shows the experimental $A_{c u}$ values of all the operating points plotted against the theoretical $A_{c u}$ values obtained from calculating the chip cross-sectional area with the corresponding interpolation data at each experimental chip thickness. With this representation, it is possible to evaluate the deviation of all the experimental operating points from the theoretical operating points by calculating the quadratic error $R^{2}$. This calculation result in a value of $R^{2}=0.95$ indicates a high interpolation quality.

\section{Mechanical single grain loads}

In the following, the force components in the normal, axial, and tangential direction at the operating points of the reference tool are examined (see Section 2 and Fig. 2). Figure 10 displays these force components at different cutting speeds dependent on the chip cross-sectional area $\mathrm{A}_{\mathrm{cu}}$.

All measured force values in Fig. 10 lie beneath $40 \mathrm{~N}$ and are comparable with values from the literature dealing with single grain cutting of tungsten carbide with diamond grains [13]. Regardless of the cutting speed, the normal, tangential, and axial forces increase linearly as the chip cross-sectional area increases. This effect is due to the increased material removal and the resulting increase in friction and material deformation energy.

In addition, it can be observed that the forces decrease as the cutting speed increases. While the normal force at the highest chip cross-sectional area and the lowest cutting speed has a value of $F_{n, 10}=29 \mathrm{~N}$, it decreases to $F_{n, 20}=19 \mathrm{~N}$ at the highest cutting speed $v_{c}=20 \mathrm{~m} / \mathrm{s}$. Furthermore, the tangential force decreases from $F_{t, 10}=38 \mathrm{~N}$ to $F_{t, 20}=21 \mathrm{~N}$ and the axial 
Fig. 7 Operating points of the reference tool

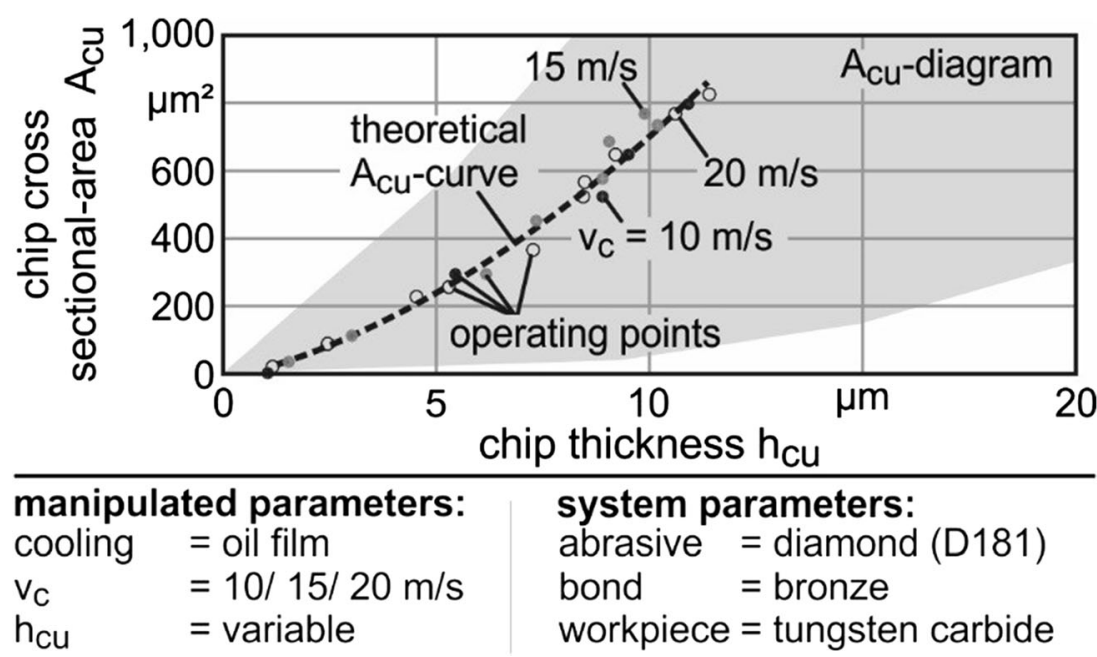

force from $\mathrm{F}_{\mathrm{a}, 10}=5.4 \mathrm{~N}$ to $\mathrm{F}_{\mathrm{t}, 10}=5.3 \mathrm{~N}$. By raising the cutting speed, the frictional power in the grain/workpiece contact zone increases which leads to higher temperatures. According to reference [13], in case of higher process temperatures, the fracture toughness and hardness of tungsten carbide and consequently the forces decrease.

The single grain-cutting force $\mathrm{F}_{\mathrm{c}}$ is suitable for the evaluation of mechanical loads which affect the grain/bond interface. It summarizes all force components and is defined by magnitude and direction:

$\overrightarrow{\mathrm{F}_{\mathrm{c}}}=\overrightarrow{\mathrm{F}_{\mathrm{n}}}+\overrightarrow{\mathrm{F}_{\mathrm{t}}}+\overrightarrow{\mathrm{F}_{\mathrm{a}}}$

As shown in Fig. 11, the single grain-cutting force increases linearly as the chip cross-sectional area increases and the cutting speed decreases, which is attributed to the development of the force components. Each test series is described by a regression line with a quadratic error over $R^{2}=0.98$ :
$\mathrm{F}_{\mathrm{c}}=\mathrm{a} \cdot \mathrm{A}_{\mathrm{cu}}+\mathrm{b}$

where $\mathrm{a}$ and $\mathrm{b}$ represent a force coefficient and a force constant, respectively. The force coefficient describes the slope of the single grain-cutting force development dependent on the chip cross-sectional area. According to the regression line, the force constant corresponds to the single grain-cutting force at the chip cross-sectional area $\mathrm{A}_{\mathrm{cu}}=0$. Regarding the machining process, this parameter can be interpreted as a plowing force acting on the grain by penetrating the workpiece surface. When the cutting speed increases from $\mathrm{v}_{\mathrm{c}}=10 \mathrm{~m} / \mathrm{s}$ to $\mathrm{v}_{\mathrm{c}}=$ $20 \mathrm{~m} / \mathrm{s}$, the force coefficient is reduced from $\mathrm{a}_{10}=0.052 \mathrm{~N} /$ $\mu \mathrm{m}^{2}$ by $39 \%$. In addition, the force constant decreases from $\mathrm{b}=7 \mathrm{~N}$ at $\mathrm{v}_{\mathrm{c}}=10 \mathrm{~m} / \mathrm{s}$ to $\mathrm{c}=2.1 \mathrm{~N}$ at $\mathrm{v}_{\mathrm{c}}=20 \mathrm{~m} / \mathrm{s}$. This cutting speed dependency of the force coefficient and the force constant is explained analogous to the correlation of the cutting speed and the resulting force components with the impact on tungsten carbide properties by higher cutting speeds.
Fig. 8 Material separation mechanisms by various chip thickness values

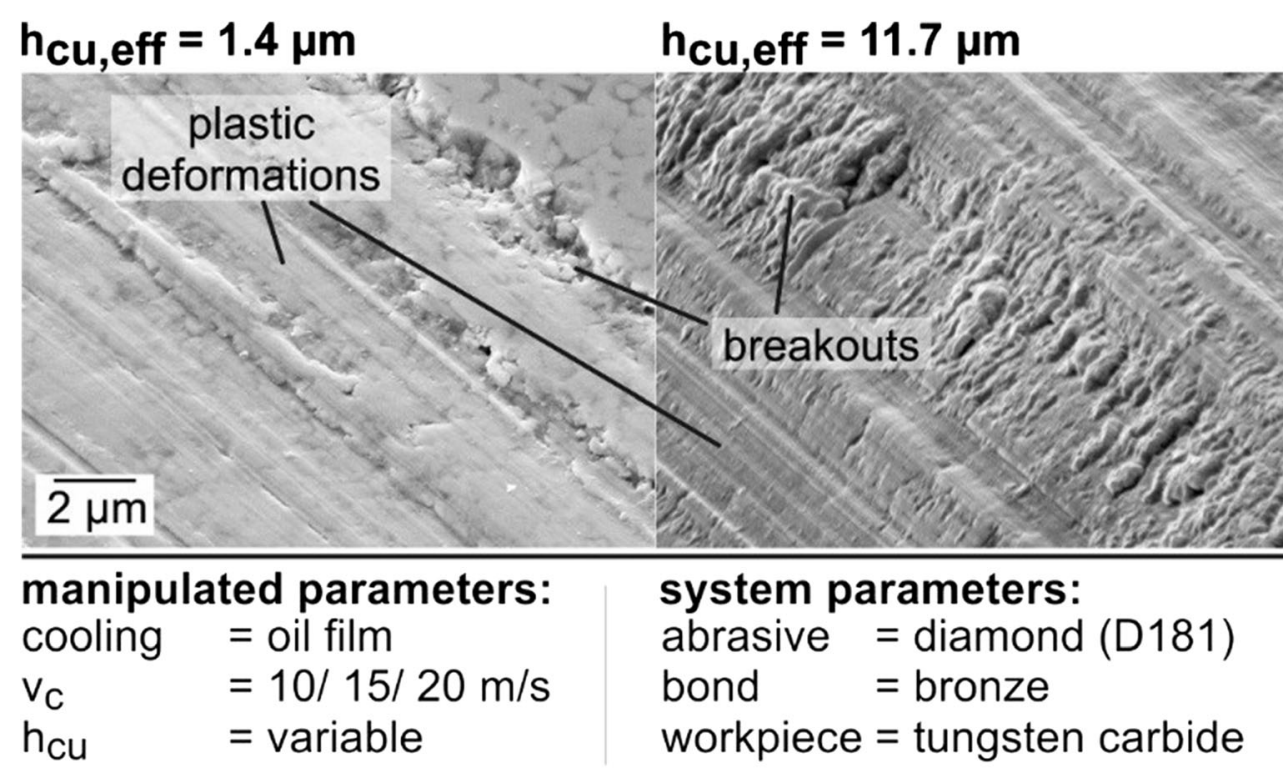



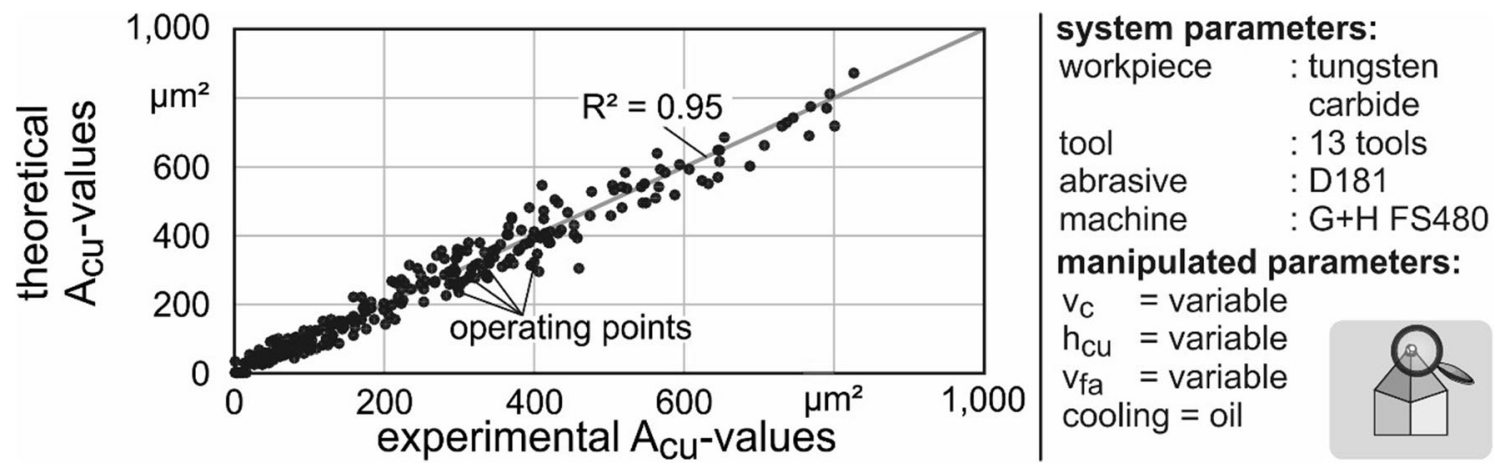

Fig. 9 Comparison of experimental and theoretical $\mathrm{A}_{\mathrm{cu}}$ values

In addition to the force magnitude, the force direction also determines the wear behavior of the abrasive grain. To characterize the force direction, the effective cutting speed angle $\eta$ is determined analogous to cutting with a geometrically determined cutting edge. Due to the three-dimensional characteristic of the single grain-cutting force, the tangential effective cutting speed angle $\eta_{\mathrm{t}}$ and the axial effective cutting speed angle $\eta_{\mathrm{a}}$ are defined as follows:

$\eta_{t}=\tan ^{-1}\left(\frac{F_{t}}{F_{n}}\right)$

$\eta_{a}=\tan ^{-1}\left(\frac{F_{a}}{F_{t}}\right)$
The tangential effective cutting speed angle is located in the tool orthogonal plane. It describes the angle between the single grain-cutting force and the normal force (Fig. 12). For the grinding process, this parameter is proportional to the cutting force ratio $\mu$. Furthermore, the axial effective cutting speed angle is situated in the cutting edge plane and corresponds to the angle between the single grain-cutting force and the tangential force (Fig. 12). Figure 12 depicts the development of these two parameters dependent on the chip cross-sectional area at different cutting speeds for the reference tool.

Figure 12 shows that the effective cutting speed angles are nearly constant over the chip cross-sectional area. The highest deviations of the measurements from the mean values occur at
Fig. 10 Force components during single gain cutting
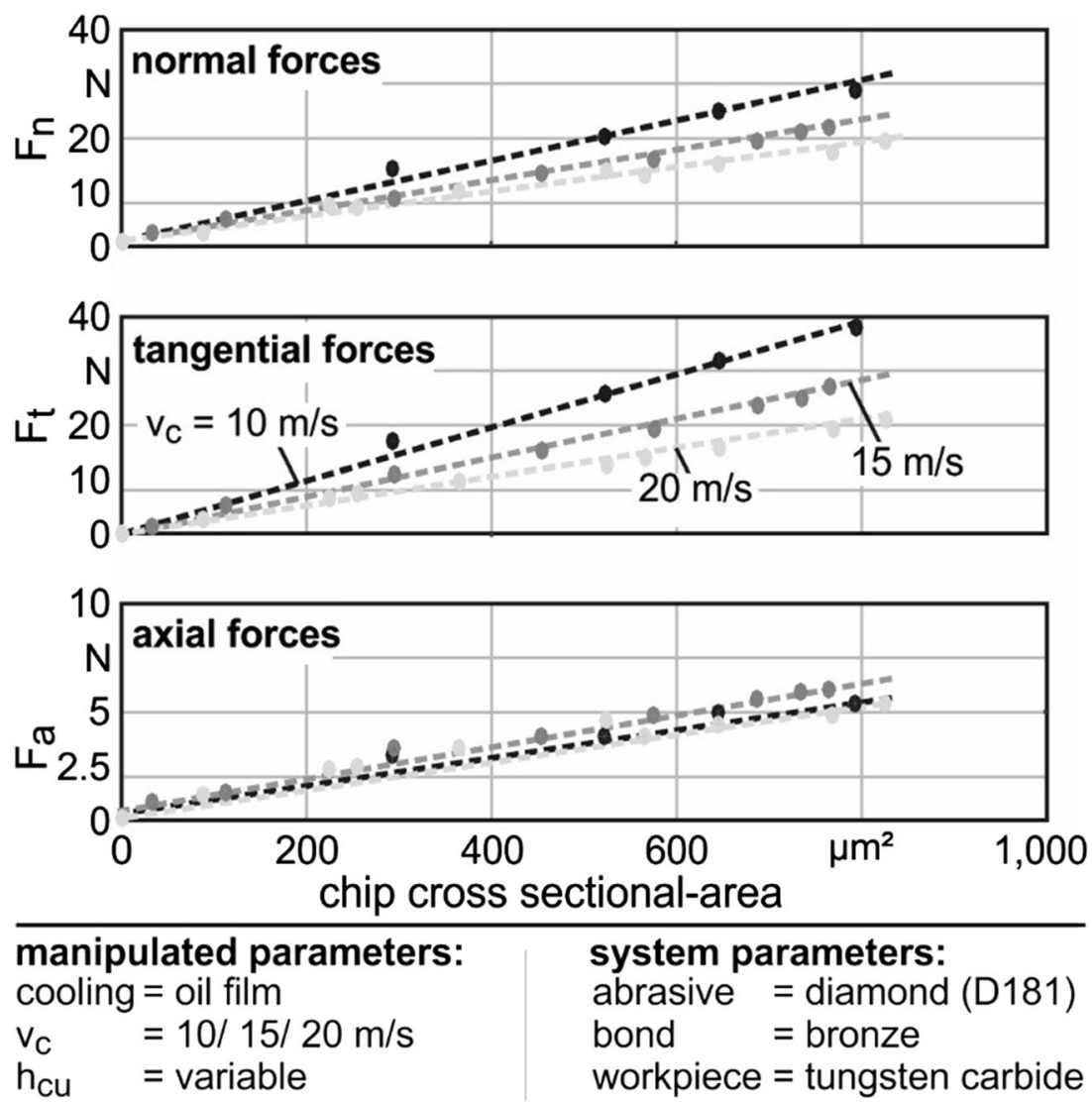
Fig. 11 Single grain-cutting force

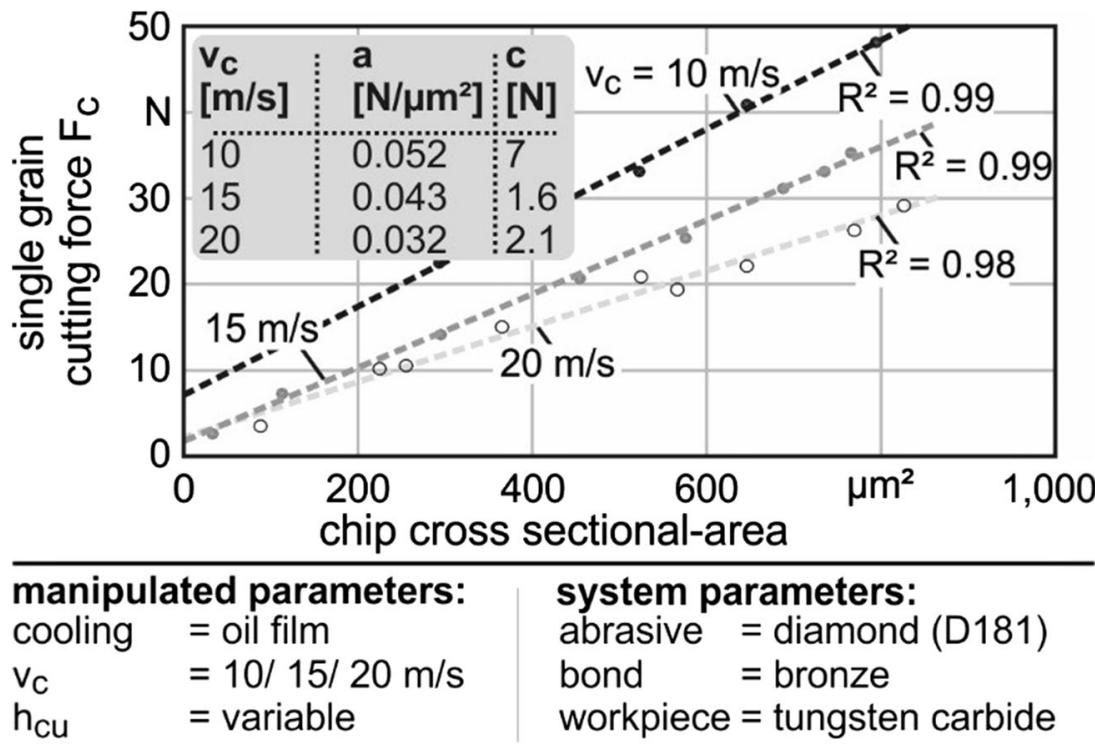

small chip cross-sectional area values. This is due to the transition from ductile to brittle material separation. Comparably with these deviations, the deviations at higher chip crosssectional area values are relatively small. These deviations are attributed to the fact that the ratio between frictional work and cutting work changes depending on the chip crosssectional area. According to Table 2 in the appendix, which shows the mean values of the effective cutting speed angles and the standard deviations of all the tools, the standard deviations are relatively small compared with the mean values for different grain orientations. Therefore, in the following, it is assumed that these parameters represent a characteristic of the cutting edge geometry which remains constant for different chip cross-sectional area values.

Additionally, Fig. 12 demonstrates that the tangential effective cutting speed angle decreases and the axial effective cutting speed angle increases by higher cutting speed values. As a result, the effect of the cutting speed on the axial effective cutting speed angle is greater than the effect on the tangential effective cutting speed angle. When the cutting speed increases from $\mathrm{v}_{\mathrm{c}}=10 \mathrm{~m} / \mathrm{s}$ to $\mathrm{v}_{\mathrm{c}}=20 \mathrm{~m} / \mathrm{s}$, the tangential effective cutting speed angle decreases from $\eta_{\mathrm{t}}=52^{\circ}$ by $8 \%$. In contrast, the axial effective cutting speed angle increases from $\eta_{\mathrm{a}}=9^{\circ}$ by $90 \%$. For the grinding tool, this cutting speed-
Fig. 12 Effective cutting speed angle

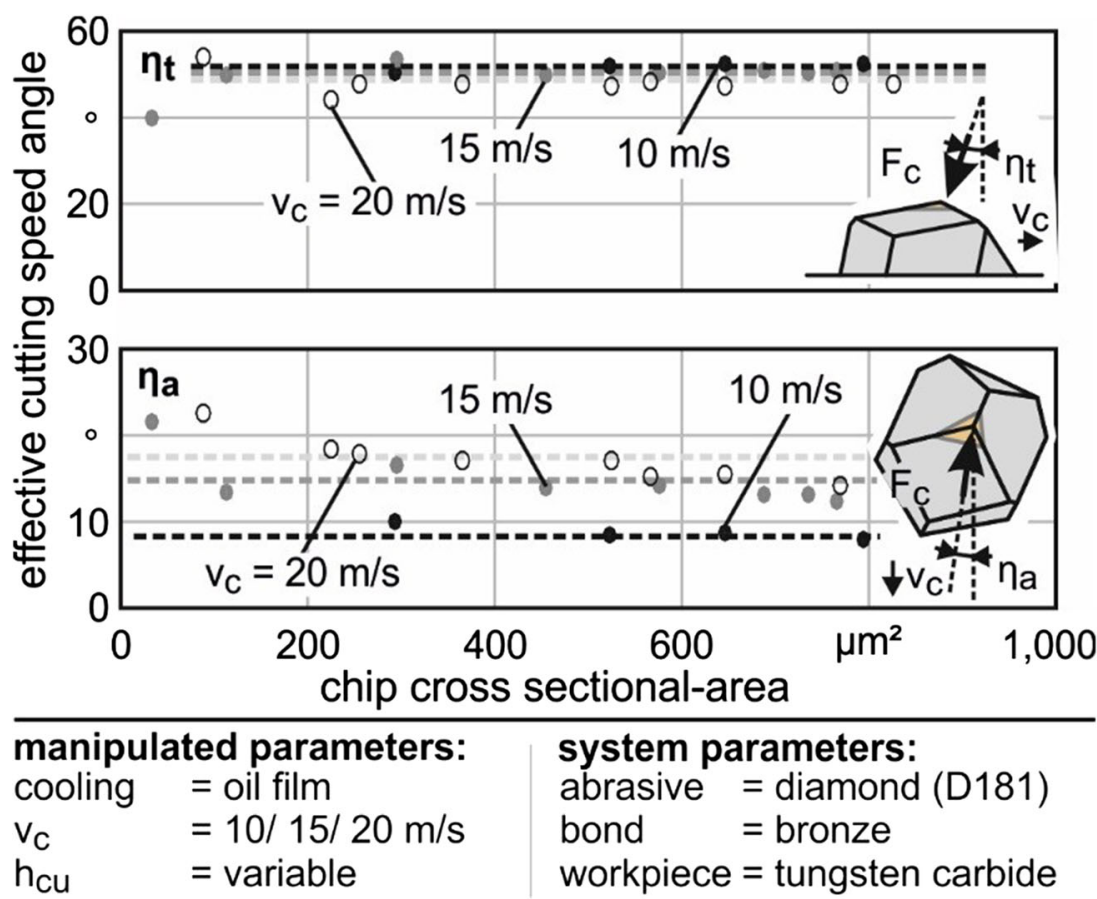




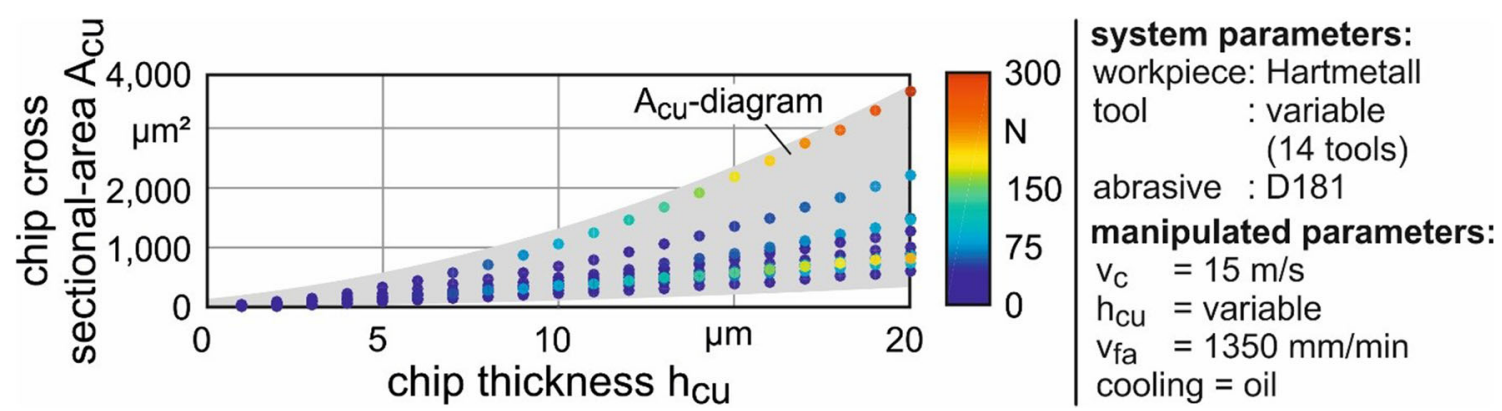

Fig. 13 Measured and calculated single grain-cutting forces

dependent development of the effective cutting speed angle causes more pressure in normal and lateral direction, which can affect the wear behavior of the grain. As shown in Table 2 in the appendix, the development of the cutting speed angles depends on the cutting edge geometry, since the tangential cutting speed angle increases and the axial effective cutting speed angle decreases by higher cutting speed values (tool 12 and tool 13).

On the basis of this exemplary consideration of the reference tool's forces, it is possible to assign a force coefficient and a force constant as well as a tangential effective cutting speed angle and an axial effective cutting speed angle to each cutting speed/tool combination. The results of these linear interpolations as well as the quadratic error and the standard deviations are shown in Table 2 in the appendix. While the quadratic error of $66 \%$ of all interpolated data is above $R^{2}=$ 0.9 , it is above 0.7 for the remaining data.

The deviations of the measured values from the regression line can be attributed to several effects. Microscopic wear of the abrasive grain or the bond can occur. Local deviations of the workpiece material properties or the lubrication conditions may also occur. In addition, the tool heats up at high chip thickness values, so that the material separation behavior is influenced.

The interpolation data shows that the findings regarding the influence of the cutting speed on the force coefficients and the force constants can be transferred to the other tools. However, the development of the effective cutting speed angle as a function of the cutting speed is geometry-dependent, since for some tools, such as tool 11 and tool 13, increasing the cutting speed leads to an increase in the tangential effective cutting speed angle and a reduction in the axial effective cutting speed angle. This difference is due to the different components of the cutting edge geometry, such as the rake angle, which are not considered in this work.

In conclusion, the effective cutting speed angles, the force coefficients, and the force constants are obtained from single grain grinding. This data can be used to define the single grain force of each tool for any chip cross-sectional area. On the other hand, interpolation results available from the previous section describe the development of the chip cross-sectional area as a function of the chip thickness (theoretical $\mathrm{A}_{\mathrm{cu}}$ curves). The combination of these results makes it possible to complement the theoretical $\mathrm{A}_{\mathrm{cu}}$ curves with the calculated single grain forces (Fig. 13). At the cutting speed $\mathrm{v}_{\mathrm{c}}=15 \mathrm{~m} / \mathrm{s}$, the highest single grain-cutting force of $300 \mathrm{~N}$ results at the highest chip thickness for flat-cutting edges. This case probably does not occur in reality because the grain would break out. However, the advantage of this diagram is that a large field in the $\mathrm{A}_{\mathrm{cu}}$ diagram can be considered, which gives an overview of the mechanical loads for different grain orientations and chip thickness values, as they occur during grinding.

\section{Conclusions}

In this paper, the single grain grinding under consideration of bond properties is developed. This method is used to define the boundary conditions at the grain/bond interface during grinding by using a single grain tool extracted from the grinding layer. The experimental investigations show that bond wear, which occurs during grinding, is formed by single grain grinding. This fact proves the suitability of the novel tool to depict the grinding process at a microscopic scale in a more realistic way than conventional single grain-cutting tools. Due to the random orientation and distribution of the abrasive grains in the grinding tool, a methodical characterization of the engagement conditions during single grain grinding is carried out. For this purpose, the chip cross-sectional area is correlated with the grain orientation. This characterization enables the creation of an $\mathrm{A}_{\mathrm{cu}}$ diagram, in which all the possible grain orientation are considered. In this diagram, an active grain during grinding is represented as an operating point. The single grain forces and the generated scratches measured in single grain grinding serve to assign forces to the operating points. These experimental findings along with the geometrical and physical tool properties will serve as input parameters to build numerical simulations to model the deformations at the grain/bond interface due to an engagement with the workpiece depending on the grain orientation and the chip thickness. 
Funding information Open Access funding provided by Projekt DEAL.

The authors thank the "Lower Saxony Ministry of Science and Culture" for their financial support within the project "Fundamentals of modelbased design and production of grinding wheels."

\section{Appendix}

Table 1 Interpolation data of $\mathrm{A}_{\mathrm{cu}}$ curves and operating points

\begin{tabular}{|c|c|c|c|c|c|c|}
\hline \multirow[t]{2}{*}{ Tool } & \multicolumn{3}{|c|}{ Interpolation data $\mathrm{A}_{\mathrm{cu}}$ course } & \multicolumn{3}{|c|}{ operating points per $\mathrm{v}_{\mathrm{c}}$} \\
\hline & $\mathrm{p}_{1}(-)$ & $\mathrm{p}_{2}(\mu \mathrm{m})$ & $R^{2}(-)$ & $10 \mathrm{~m} / \mathrm{s}$ & $15 \mathrm{~m} / \mathrm{s}$ & $20 \mathrm{~m} / \mathrm{s}$ \\
\hline Reference & 4.315 & 27.279 & 0.98 & 5 & 8 & 10 \\
\hline 2 & 3.514 & 5.808 & 0.95 & 14 & 10 & 9 \\
\hline 3 & 8.321 & 25.084 & 0.92 & 8 & 4 & 8 \\
\hline 4 & 1.304 & 26.226 & 1 & 5 & 11 & 0 \\
\hline 5 & 0.281 & 32.495 & 0.89 & 7 & 5 & 8 \\
\hline 6 & 0.891 & 27.672 & 0.98 & 18 & 8 & 2 \\
\hline 7 & 1.351 & 33.092 & 0.91 & 6 & 0 & 0 \\
\hline 8 & 1.667 & 51.12 & 0.93 & 16 & 11 & 11 \\
\hline 9 & 0.57 & 31.32 & 0.91 & 11 & 5 & 3 \\
\hline 10 & 0.841 & 14.069 & 0.99 & 0 & 3 & 4 \\
\hline 11 & 2.489 & 25.114 & 0.96 & 10 & 5 & 9 \\
\hline 12 & 2.175 & 22.448 & 0.96 & 17 & 8 & 5 \\
\hline 13 & 1.881 & 9.006 & 0.95 & 12 & 11 & 11 \\
\hline
\end{tabular}

Table 2 Interpolation data of single grain forces and effective cutting speed angles

\begin{tabular}{|c|c|c|c|c|c|c|c|c|}
\hline \multirow[t]{2}{*}{$\mathrm{v}_{\mathrm{c}}(\mathrm{m} / \mathrm{s})$} & \multirow[t]{2}{*}{ Tool } & \multicolumn{3}{|c|}{ Single grain force } & \multicolumn{2}{|c|}{$\begin{array}{l}\text { Tangential effective } \\
\text { cutting speed angle }\end{array}$} & \multicolumn{2}{|c|}{$\begin{array}{l}\text { Axial effective } \\
\text { cutting speed angle }\end{array}$} \\
\hline & & $a\left(N / \mu m^{2}\right)$ & $\mathrm{b}(\mathrm{N})$ & $R^{2}$ & $\eta_{\mathrm{t}}\left({ }^{\circ}\right)$ & stb. $\left({ }^{\circ}\right)$ & $\eta_{\mathrm{a}}\left({ }^{\circ}\right)$ & stb. $\left({ }^{\circ}\right)$ \\
\hline \multirow[t]{8}{*}{10} & Ref. & 0.06 & 4. 5 & 0.99 & 52 & 0.9 & 9 & 0.7 \\
\hline & 2 & 0.08 & 2 & 0.89 & 21 & 6 & 28 & 4 \\
\hline & 4 & 0.04 & 0.6 & 0.97 & 27 & 1 & 11 & 1.3 \\
\hline & 6 & 0.09 & 4.9 & 0.88 & 10 & 0.6 & 51 & 2.8 \\
\hline & 7 & 0.03 & 19.9 & 0.78 & 25 & 0.3 & 27 & 1.1 \\
\hline & 11 & 0.13 & 1.7 & 0.90 & 20 & 1.2 & 34 & 2.2 \\
\hline & 12 & 0.05 & 8.9 & 0.7 & 34 & 1.3 & 22 & 2 \\
\hline & 13 & 0.04 & 0.9 & 0.99 & 22 & 2.4 & 24 & 6.4 \\
\hline \multirow[t]{11}{*}{15} & Ref. & 0.04 & 1.6 & 0.99 & 49 & 3.7 & 16 & 4.5 \\
\hline & 2 & 0.04 & 2.3 & 0.98 & 17 & 4 & 44 & 3.6 \\
\hline & 3 & 0.1 & 0.6 & 0.99 & 29 & 4 & 16 & 0.3 \\
\hline & 4 & 0.03 & 1.1 & 0.93 & 27 & 4 & 29 & 14 \\
\hline & 5 & 0.17 & 4.7 & 0.8 & 18 & 3.8 & 46 & 13.1 \\
\hline & 6 & 0.14 & 2.8 & 0.94 & 18 & 4.2 & 48 & 14 \\
\hline & 9 & 0.32 & 9.1 & 0.87 & 63 & 1.6 & 9 & 2.2 \\
\hline & 10 & 0.03 & 0.7 & 0.82 & 14 & 0.3 & 37 & 18 \\
\hline & 11 & 0.08 & 0.1 & 0.98 & 27 & 3.4 & 31 & 8 \\
\hline & 12 & 0.03 & 0.6 & 0.98 & 45 & 1.8 & 12 & 3.4 \\
\hline & 13 & 0.03 & 0.7 & 0.99 & 24 & 2.2 & 30 & 6.2 \\
\hline \multirow[t]{9}{*}{20} & Ref. & 0.03 & 1.2 & 0.98 & 48 & 2.4 & 17 & 2.5 \\
\hline & 2 & 0.03 & 1.7 & 0.94 & 13 & 1.9 & 50 & 8.9 \\
\hline & 3 & 0.07 & 0.7 & 0.99 & 24 & 3 & 25 & 14 \\
\hline & 5 & 0.16 & 1.4 & 0.96 & 24 & 2.7 & 33 & 7.9 \\
\hline & 9 & 0.16 & 1.5 & 0.87 & 60 & 1.8 & 8 & 1.2 \\
\hline & 10 & 0.01 & 0.1 & 0.88 & 24 & 1.6 & 44 & 15 \\
\hline & 11 & 0.06 & 0.6 & 0.97 & 13 & 2.4 & 50 & 10.3 \\
\hline & 12 & 0.03 & 0.03 & 0.99 & 42 & 2.8 & 18 & 1 \\
\hline & 13 & 0.02 & 0.03 & 0.99 & 28 & 2.2 & 32 & 7.4 \\
\hline
\end{tabular}


Open Access This article is licensed under a Creative Commons Attribution 4.0 International License, which permits use, sharing, adaptation, distribution and reproduction in any medium or format, as long as you give appropriate credit to the original author(s) and the source, provide a link to the Creative Commons licence, and indicate if changes were made. The images or other third party material in this article are included in the article's Creative Commons licence, unless indicated otherwise in a credit line to the material. If material is not included in the article's Creative Commons licence and your intended use is not permitted by statutory regulation or exceeds the permitted use, you will need to obtain permission directly from the copyright holder. To view a copy of this licence, visit http://creativecommons.org/licenses/by/4.0/.

\section{References}

1. Klocke F (2009) Manufacturing processes 2 (grinding, honing, lapping). Springer-Verlag, Berlin Heidelberg. https://doi.org/10.1007/ 978-3-540-92259-9

2. Tönshoff H, Denkena B (2013) Basics of cutting and abrasive processes. Springer-Verlag, Berlin Heidelberg. https://doi.org/10.1007/ 978-3-642-33257-9

3. Denkena B, Grove T, Bremer I, Behrens L (2016) Design of bronze bonded grinding wheel properties. CIRP Ann Manuf Technol 65(1): 333-336. https://doi.org/10.1016/j.cirp.2016.04.096

4. Schatt W (1992) Sintervorgänge: Grundlagen. VDI-Verlag, Düsseldorf

5. Artini C, Muolo M, Passerone A (2012) Diamond-metal interfaces in cutting tools: a review. J Mater Sci:3252-3264. https://doi.org/ 10.1007/s10853-011-6164-6

6. Maargaritis DP (2003) Interfacial bonding in metal-matrix composites reinforced with metal-coated diamonds. University of Nottingham. Ph.D. thesis

7. Tönshoff HK, Peters J, Inasaki I, Paul T (1992) Modelling and simulation of grinding processes. Ann CIRP 41

8. Nakayama K, Takagi J, Irie E, Okuno K (1980) Sharpness evaluation of grinding wheel face by the grinding of steel ball. Ann CIRP 29(1)

9. Rasim M (2015) Modellierung der Wärmeentstehung im Schleifprozess in Abhängigkeit von der Schleifscheibentopographie. Rheinisch-Westfälischen Technischen Hochschule Aachen. Dr-Ing. Dissertation
10. Durgumahanti UP, Singh V, Rao PV (2009) A new model for grinding force prediction and analysis. Int J Mach Tool Manu 50:231240. https://doi.org/10.1016/j.ijmachtools.2009.12.004

11. Uhlmann E, Koprowski S, Weingaertner WL, Rolon DA (2016) Modeling and simulation of grinding processes with mounted points: part II of II - fast modeling method for workpiece surface prediction. 7th HPC 216 - CIRP Conference on High Performance Cutting 46:603-606. https://doi.org/10.1016/j.procir.2016.03.202

12. Holtermann R, Menzel A, Schumann S, Biermann D, Siebrecht T, Kersting P (2015) Modelling and simulation of internal traverse grinding: bridging meso- and macro-scale simulations. Prod Eng Res Devel 9:451-463. https://doi.org/10.1007/s11740-015-0613-Z

13. Wirtz C (2018) Zerspanverhalten von WC-Co Hartmetallen bei der Schleifbearbeitung. Rheinisch-Westfälische Technische Hochschule. Dr.-Ing. Dissertation

14. Gee MG, Nunn J, Mingrad K, Roebuck B (2016). In situ scratch testing of WC/Co hardmetals. World PM2016 - Characterisations and Properties II

15. Aurich J, Steffes M (2011) Single grain scratch tests to determine elastic and plastic material behavior in grinding. Adv Mater Res 325:48-53. https://doi.org/10.4028/www.scientific.net/AMR.325. 48

16. Oepoez TT, Chen X (2012) Experimental investigation of material removal mechanism in single grit grinding. Int J Mach Tool Manu 63:32-40. https://doi.org/10.1016/j.ijmachtools.2012.07.010

17. Brinksmeier E, Giwerzew A (2003) Chip formation mechanisms in grinding at low speeds. CIRP Ann Manuf Technol 52(1):253-258. https://doi.org/10.1016/S0007-8506(07)60578-2

18. Wang H, Subhash G, Chandra A (2001) Characteristics of singlegrit rotating scratch with a conical tool on pure titanium. Wear 249: 566-581. https://doi.org/10.1016/S0043-1648(01)00585-3

19. Anderson D, Warkentin A, Bauer R (2011) Experimental and numerical investigations of single abrasive-grain cutting. Int J Mach Tool Manu 51:898-910. https://doi.org/10.1016/j.ijmachtools. 2011.08.006

20. Giwerzew A (2003) Spanbildungsmechanismen und tribologisches Prozessverhalten beim Schleifen mit niedrigen Schnittgeschwindigkeiten. Universität Bremen. Dr.-Ing. Dissertation

21. Lierse T (1998) Mechanische und thermische Wirkungen beim Schleifen keramischer Werkstoffe. Universität Hannover. Dr.-Ing. Dissertation

Publisher's note Springer Nature remains neutral with regard to jurisdictional claims in published maps and institutional affiliations. 